\title{
O Programa de Educação Tutorial (PET) e a formação docente em química: investigando aprendizagens a partir de narrativas
}

\author{
Wilmo Ernesto Francisco Junior ${ }^{1}$ \\ Neila da Silva Paschoal ${ }^{2}$ \\ Maria Jeane Vieira da Silva ${ }^{3}$
}

Resumo

Este estudo investigou aprendizagens e o impacto do Programa de Educação Tutorial (PET) na formação de licenciandos em química. Como método da pesquisa foram empregadas narrativas reflexivas sobre a participação no programa, avaliadas sob a perspectiva da análise de conteúdo. Quatro temas gerais que favoreceram aprendizagens foram identificados: o trabalho coletivo, a interação com comunidade(s), experiências individuais singulares, perspectivas de futuro. As aprendizagens concentraram-se em aspectos atitudinais e procedimentais com menção não explícita sobre a dimensão conceitual. As narrativas demonstraram-se úteis para a análise de contribuições formativas, podendo se configurar em uma atividade reflexiva que proporciona a (auto)avaliação de programas educacionais similares.

Palavras-chave: Educação Tutorial; Ensino Superior; Formação de Professores de Química.

\section{The Program of Tutorial Education (PET) and the chemistry teacher education: investigating learnings from} narratives

\begin{abstract}
This study investigated learnings and the impacts from Program of Tutorial Education on the instructive process of chemistry students. The research method included narratives about the participation in the program that were analyzed using content analysis. It was identified four general themes as contributions of the tutorial education on learning: collective working. integration with communities, individual experiences and future perspectives. The learning of attitudinal and procedural aspects came out more frequently. Conceptual dimension was mentioned, but evidences were not presented. The narratives demonstrated to be a good tool for learning analytics, and they may be a reflexive activity in order to contribute for (self)evaluation of educational programs with similar characteristics.

Keywords: Tutorial Education; Higher Education; Chemistry Teacher Education.
\end{abstract}

\section{Introdução}

A universidade brasileira é caracterizada pelo princípio da indissociabilidade entre ensino, pesquisa e extensão, princípios estes afirmados tanto na Constituição Federal de 1988 quanto na Lei de Diretrizes e Bases de 1996 (BRASIL, 1996). Soma-se a isso o Plano Nacional da Educação

\footnotetext{
${ }^{1}$ Universidade Federal de Alagoas/UFAL, Arapiraca, wilmojr@gmail.com

2 Universidade Federal de Alagoas/UFAL, Arapiraca, neilapaschoal@gmail.com

${ }^{3}$ Universidade Federal de Alagoas/UFAL, Arapiraca, jeanevieirads@gmail.com
} 
(PNE) aprovado para o decênio 2014-2024 (BRASIL, 2014) que prevê a destinação de 10\% da carga horária de todos os cursos superiores às atividades de extensão, com o intuito de favorecer a inserção social da universidade. Nessa perspectiva, impinge-se à universidade e seus agentes pensar em programas, projetos e ações capazes de atuar não de maneira eventual ou isolada, mas organicamente e organizadamente para que tais princípios sejam materializados.

Mesmo antes da promulgação de tais documentos, foi criado em 1979 o Programa de Educação Tutorial - PET (inicialmente Programa Especial de Treinamento), explicitamente pautado pelo viés integrador entre ensino, pesquisa e extensão. Até 1999 o programa foi gerenciado pela Coordenação de Aperfeiçoamento de Pessoal de Nível Superior (CAPES), principal agência brasileira de fomento e ligada ao Ministério da Educação, passando desde então à Secretaria de Ensino Superior (SESu) e ao Fundo Nacional de Desenvolvimento da Educação (FNDE), também do mesmo Ministério.

Quanto à organização, o PET pode ser formado a partir de qualquer curso específico de graduação, bem como interdisciplinarmente, em que estudantes de diferentes cursos participam tendo um foco específico, por exemplo, Ciência \& Tecnologia (BRASIL, 2013). Cada grupo é composto de 12 estudantes de graduação bolsistas e mais um docente tutor, todos aprovados por seleção organizada pela Instituição de Ensino Superior. Estudantes não bolsistas também podem ser admitidos, devendo passar igualmente por processo de seleção e cumprir as atividades regulares. Anualmente, o grupo é avaliado interna (por comissão específica da universidade) e externamente (por técnicos do Ministério da Educação) mediante a apresentação de planejamento e do relatório de execução das ações anuais. O planejamento anual é encaminhado contendo a descrição, objetivos, justificativa, resultados esperados e forma de avaliação de cada ação a ser desenvolvida no ano subsequente. 0 relatório diz respeito à avaliação e análise das ações realizadas no ano anterior, sempre correspondendo ao planejamento proposto.

No que tange à atuação, o programa é fundamentado, sobretudo, a partir da indissociabilidade entre ensino, pesquisa e extensão, bem como na natureza coletiva e interdisciplinar das ações. São oito os objetivos do PET de acordo com sua regulamentação legal (BRASIL, 2013): I) desenvolver atividades acadêmicas com elevados padrões de qualidade; II) contribuir para a elevação da qualidade da formação acadêmica da graduação; 
III) estimular a formação de profissionais e docentes com qualificação técnica, científica, tecnológica e acadêmica; IV) formular novas estratégias de desenvolvimento e modernização do ensino superior; V) estimular o espírito crítico, a atuação profissional pautada pela cidadania e pela função social da educação superior; VI) introduzir novas práticas pedagógicas na graduação; VII) contribuir para a consolidação e difusão da educação tutorial como prática de formação na graduação e; VIII) contribuir com a política de diversidade no ensino superior por meio de ações afirmativas em defesa da equidade socioeconômica, étnico-racial e de gênero.

Para tal, o aspecto central do desenvolvimento das atividades do PET é a educação tutorial. Etimologicamente, o termo tutoria tem origem no latim tutari, que significa proteger/defender. O conceito de tutoria parece ter surgido na mitologia grega (BRUTTEN, 2008). O tutor era visto como alguém ungido com a proteção divina. No campo jurídico o exercício da tutela caracterizou-se pela função de zelar por alguém fora da proteção do pátrio poder. Em termos educacionais, o termo ganhou contornos a partir do renascentismo com características de uma assistência personalizada entre alguém mais experiente e outro com necessidades de aprendizagem (BRUTTEN, 2008). Entretanto, com o passar dos anos a tutoria passou a assumir diferentes formas de ação no campo educacional, entre elas: ação acadêmica ou formativa (com ênfase na aprendizagem autônoma e criativa); assistência personaliza da (apoio pedagógico a estudantes que apresentam dificuldades); acompanhamento em período de práticas (comum em cursos de profissionalização); orientação à distância (própria do ensino não-presencial); apoio e atenção na diversidade (oferecer oportunidades iguais aos alunos); promoção de aprendizagens entre estudantes (desenvolvimento acadêmico) (CARABALLO, 2012).

Em todas suas vertentes, o processo de tutoria caracteriza-se pela orientação de atividades sistematicamente organizadas com vistas ao desenvolvimento de diversas capacidades dos sujeitos envolvidos. Lazaro Martines (1997) argumenta que a tutoria, na atualidade, é um aspecto chave na relação entre docentes e discentes, principalmente na universidade. A tutoria acadêmica busca uma relação entre o ensino e a pesquisa (CARABALLO, 2012). É dentro deste contexto que está inserido o PET. Nesses termos, em consonância aos preceitos legalmente vigentes, a educação tutorial no programa se configura basicamente 
mediante o trabalho coletivo, dialógico e horizontal em que estudantes e docentes assumem o protagonismo e as responsabilidades do processo. Tais características são essenciais para que todos os envolvidos se desenvolvam em um processo capaz de proporcionar diversas aprendizagens, seja na dimensão social, pessoal, intelectual e afetiva. Assim, o professor tutor e os estudantes petianos são co-responsáveis pelo planejamento, execução e avaliação de atividades que tenham como público tanto a comunidade acadêmica quanto, principalmente, aquela não universitária. O tutor atua como coordenador, ensinando por meio da experiência, do saber sistematizado, do diálogo e de suas ações, estimulando o desenvolvimento da autonomia intelectual. Por sua vez, os estudantes enquanto aprendem também ensinam. Podese inferir, portanto, que tal concepção de educação tutorial coaduna-se à perspectiva freiriana de educador-educando e educando-educador que aprendem em comunhão.

Em verdade, não seria possível a educação problematizadora, que rompe com os esquemas verticais característicos da educação bancária, realizar-se como prática da liberdade, sem superar a contradição entre o educador e os educandos. Como também não Ihe seria possível fazê-lo fora do diálogo. É através deste que se opera a superação de que resulta um termo novo: não mais educador do educando, não mais educando do educador, mas educadoreducando com educando-educador. Desta maneira, o educador já não é o que apenas educa, mas o que, enquanto educa, é educado, em diálogo com o educando que, ao ser educado, também educa. Ambos, assim, se tornam sujeitos do processo em que crescem juntos (...). Já agora ninguém educa ninguém, como tampouco ninguém se educa a si mesmo: os homens se educam em comunhão, mediatizados pelo mundo (FREIRE, 2005, p.78-79).

O autor concebe o diálogo como ponto de partida de qualquer processo educativo, considerando ao mesmo tempo um processo em que os sujeitos se educam. O processo de tutoria também está fortemente arraigado no diálogo. Quem ensina está a aprender neste processo, do mesmo modo que aquele que aprende, também ensina. A educação tutorial pode ser vista, nesses termos, como um processo de natureza político-educativa com vistas ao desenvolvimento da autonomia de ação e pensamento dos envolvidos, comungando, portanto, do pensamento freiriano.

Considerando as possibilidades de ações a partir do PET, vislumbra-se um espaço concreto para a promoção de atividades que venham a colaborar na integração teoria-prática, especialmente no desenvolvimento de conteúdos de aprendizagem de seus integrantes. Assim 
como Zabala (1998), não se entende aqui os conteúdos de aprendizagem no sentido restrito, mas em um contexto amplo, isto é, como "todos aqueles que possibilitem o desenvolvimento das capacidades motoras, afetivas, de relação interpessoal e de inserção social” (p.30). Portanto, é importante que o estudante vivencie experiências em que seja o protagonista da construção do conhecimento e desenvolvimento cognitivo, fugindo do modelo de transferência de conhecimento.

Neste sentido, o programa pode atuar favoravelmente interligando a formação e as futuras práticas profissionais, pois oportuniza aos estudantes o enfrentamento de diferentes realidades e a reflexão sobre os impactos dessas ações, favorecendo a apropriação dos conteúdos que se relacionem àquilo que devem saber (conceitos), o que devem saber fazer (procedimentos), assim como ao que devem ser (atitudes), respectivamente os conteúdos conceituais, procedimentais e atitudinais (ZABALA, 1998). Frente a isso, é incoerente que os projetos desenvolvidos no programa se configurem por uma perspectiva bancária de ensino.

Nesse contexto insere-se ainda as especificidades de cada grupo de Educação de Tutorial. No caso particular deste trabalho, trata-se de um grupo formado por um curso específico, de Licenciatura em Química, sediado em um dos campi de uma universidade federal no Nordeste do Brasil que foi criado em 2007 a partir do REUNI (Programa de Reestruturação e Expansão das Universidades Federais). Em virtude deste grupo constituir-se no seio de um curso de formação de professores, suas atividades são desenvolvidas com vistas ao atendimento de um processo formativo que integre ensino-pesquisa-extensão em ações pedagógicas, promovendo a inserção dos estudantes em atividades de ensino, bem como fomentando reflexões teóricas a partir das atividades práticas arroladas. Ou seja, saberes necessários à prática educativa que fomentem o desenvolvimento da autonomia dos petianos.

O objetivo desta pesquisa foi justamente avaliar as contribuições do PET no que se refere à formação destes licenciandos a partir da (auto)análise de suas aprendizagens. A pesquisa teve como guia o seguinte problema: Qual(is) o(s) impacto(s) do PET na formação e aprendizagens dos seus participantes considerando as especificidades de um curso de licenciatura? Almejando responder tal questão, foi proposta a narrativa como ferramenta de (auto)análise e (auto)regulação educacional. 


\section{Procedimentos Metodológicos}

Este é um estudo de natureza empírica e qualitativa cujo foco é a (auto)análise das aprendizagens e dos impactos do Programa de Educação Tutorial na formação superior de licenciados em química. Participaram 12 estudantes petianos (10 do sexo feminino e 2 do sexo masculino) de um curso de licenciatura em química de uma universidade federal localizada no interior de um Estado do Nordeste brasileiro. A média de idade era de 22,4 anos, com um intervalo de 19 anos e 8 meses a 30 anos e 11 meses. Pelo fato de o PET ser um programa formativo de longo prazo, os participantes deveriam ter um tempo mínimo de seis meses de permanência, de modo a já terem desenvolvido todas as ações previstas no planejamento anual ao menos em uma oportunidade.

Para a coleta de dados foi solicitada a elaboração de um texto narrativo, sendo informada a intencionalidade desta pesquisa, bem como o uso das informações para a (auto)avaliação do programa. Foi solicitado que escrevessem sobre suas experiências no programa e qual a importância das atividades desenvolvidas para o processo formativo. As produções foram realizadas individualmente e em um tempo médio de 10 dias. Foram produzidos ao total 12 textos, sendo 11 deles de integrantes bolsistas e 1 de um integrante não-bolsista do programa. A fim de manter o anonimato, as produções receberam nomes fictícios. O estudo se enquadra dentro de duas ações do PET, a pesquisa de caráter coletivo e a (auto)avaliação, que são atividades obrigatórias do programa, da qual os petianos precisam participar e dão anuência quando da assinatura dos termos de compromisso de bolsista. Ainda assim, a participação nesta pesquisa através da produção da narrativa foi espontânea e consentida.

A ideia da elaboração de um texto aberto possibilitou que as reflexões dos petianos fossem livres e que, contando suas experiências mediante a escrita, assumissem características históricas e reflexivas, que é de grande relevância a formação docente ao propiciar ao escritor novas interpretações das próprias experiências, de si e dos outros (CUNHA, 1997). Este exercício é ligado ao afetivo e a forma como o sujeito percebe seu desenvolvimento em tarefas, proporcionando reflexões e sentimentos a respeito do pensamento (RIBEIRO, 2003). A partir da escrita, os integrantes do programa ponderam e pensam sobre as potencialidades das atividades desenvolvidas em sua formação. 
Para o exame das produções recorreu-se à análise de conteúdo (BARDIN, 2011), realizada em 3 etapas básicas: pré-análise, exploração do material e interpretação dos dados. O processo foi auxiliado pelo software de análise qualitativa MAXQDA ${ }^{\circledR}$ (versão 2018). Este programa oferece uma interface que consiste de quatro janelas. Em uma delas são inseridos os dados do projeto, os textos e grupos de textos (sistema de documentos). Em outra se insere a estrutura de códigos e categorias (código do sistema). Uma terceira permite editar e consultar textos (navegador de documentos) e a última fornece a possibilidade de realizar buscas e verificações em relação ao material codificado (segmentos recuperados). As categorias precisam ser definidas previamente para permitir a inserção no sistema e são controladas pelo usuário. Todavia, podem ser modificadas ao longo do processo, além da possibilidade de hierarquização, customização de cores para os códigos e associação de variáveis.

Inicialmente foi realizada uma leitura flutuante que permitiu identificar alguns descritores principais. Esses descritores foram inseridos no software, o que permitiu codificar, acessar e separar os trechos para análise. Em seguida os textos foram relidos integralmente com a decodificação do conteúdo informativo, refinamento e agrupamento dos descritores. Após, foi efetuada a separação dos temas principais (impactos do PET na formação) e das categorias de aprendizagens que permitiram a interpretação preliminar. Após o estabelecimento das temáticas gerais que impactam a formação e contribuem com a aprendizagem, procedeu-se à análise descritiva. Para o aumento da consistência, a análise ocorreu independentemente por duas pesquisadoras. Casos divergentes ou dúbios foram discutidos com um terceiro pesquisador.

A discussão dos resultados levou em consideração a tipologia de conteúdos de aprendizagem (ZABALA, 1998), bem como o pensamento freiriano, além de contribuições sobre a formação docente em química (MALDANER, 2006).

\section{Resultados e Discussão}

\section{Aspectos gerais}

Em um primeiro momento, os resultados evidenciaram quatro temas gerais que podem ser elencados como os impactos do PET no processo formativo de seus participantes: o trabalho 
coletivo, a interação com a(s) comunidades, experiências individuais singulares, perspectivas de futuro. Tais temas correspondem ao que os petianos vivenciaram e sobre como foram modificados enquanto sujeitos durante o processo. De tal forma, os temas gerais são também características constitutivas do PET na condição de um programa formativo. Cada tema geral apresentou descritores em comuns e unidades de significado que permitiram identificar aprendizagens. Por sua vez, tais aprendizagens foram agrupadas conforme sua natureza (conceitual, procedimental, atitudinal). Estas informações foram reunidas no Quadro 1 de modo a permitir uma visão geral. Vale destacar que tais temas não representam uma separação fixa, pois configuram o mesmo processo formativo. Assim, devem ser compreendidos como categorias analíticas que permitem uma interpretação do processo formativo e muitas vezes entrecruzam-se.

Quadro 1. Temas gerais, descritores e aprendizagens identificadas a partir das narrativas.

\begin{tabular}{|c|c|c|c|}
\hline $\begin{array}{l}\text { Temas gerais - } \\
\text { Impactos do PET } \\
\text { na formação }\end{array}$ & $\begin{array}{c}\text { Principais } \\
\text { descritores/número } \\
\text { de menções }\end{array}$ & Aprendizagens identificadas & $\begin{array}{l}\text { Natureza das } \\
\text { aprendizagens }\end{array}$ \\
\hline $\begin{array}{l}\text { Trabalho coletivo: } \\
\text { o PET como grupo }\end{array}$ & Grupo - 29 & $\begin{array}{l}\text { Respeito/capacidade de ouvir } \\
\text { outras opiniões; } \\
\text { Comunicação (falar com o } \\
\text { outro e em público); } \\
\text { Convivência/saber } \\
\text { ouvir/dialogar; Argumentação }\end{array}$ & $\begin{array}{l}\text { Atitudinais e } \\
\text { procedimentais }\end{array}$ \\
\hline $\begin{array}{l}\text { Interação com a(s) } \\
\text { comunidades }\end{array}$ & $\begin{array}{l}\text { Extensão }-19 \\
\text { Público/alunos (de } \\
\text { escolas) }-13 \\
\text { Comunidade }-9\end{array}$ & $\begin{array}{l}\text { Lidar com o público } \\
\text { (comunicação); } \\
\text { Capacidade de } \\
\text { identificação/análise do meio } \\
\text { social/realidade }\end{array}$ & $\begin{array}{l}\text { Procedimentais } \\
\text { (predominante) } \\
\text { e atitudinais }\end{array}$ \\
\hline $\begin{array}{c}\text { Desenvolvimento } \\
\text { pessoal }\end{array}$ & $\begin{array}{l}\text { Experiências - } 13 \\
\text { Exercer } \\
\text { docência/ensino - } 10 \\
\text { Oportunidade (de } \\
\text { realizar tarefa nova) - } \\
7 \\
\text { Aprendizado - } 6\end{array}$ & $\begin{array}{l}\text { Respeito a individualidades; } \\
\text { Comunicação; } \\
\text { Organização/realização e } \\
\text { responsabilidade por tarefas; } \\
\text { Mediação pedagógica; } \\
\text { Interpretação textual; } \\
\text { Revisão de conceitos; } \\
\text { Análise do contexto/sociedade, }\end{array}$ & $\begin{array}{l}\text { Conceituais (não } \\
\text { explicitado), } \\
\text { atitudinais, } \\
\text { procedimentais }\end{array}$ \\
\hline $\begin{array}{l}\text { Perspectivas } \\
\text { futuras }\end{array}$ & Futuro -9 & Planejamento pessoal & Atitudinais \\
\hline
\end{tabular}

Fonte: Os autores. 
O trabalho coletivo foi um tema geral de grande destaque. O termo grupo foi o descritor mais presente, aparecendo em $91.7 \%$ das narrativas (29 citações), tanto para se referir a aprendizagens quanto às ações realizadas. A interação com a(s) comunidade(s) foi um tema destacado em função das ações e atividades com o público. Assim, extensão, público/alunos e comunidade foram as principais menções. O desenvolvimento pessoal por meio das diferentes experiências suscitadas também emergiu, sublinhando o impacto das experiências proporcionadas pelo programa na formação individual. Os termos "experiências" e "oportunidade", por exemplo, foram mencionados 13 (treze) e 7 (sete) vezes, respectivamente. O desenvolvimento de aprendizagens ligadas à docência também se destacou nessa temática, sendo discutido em 8 narrativas (66,7\%). Por fim, as perspectivas de futuro também apareceram como elemento impactante, revelando que o programa também auxilia a (re)pensar suas atividades após a graduação. Cinco narrativas apresentaram alguma reflexão dessa natureza.

Desses resultados é possível inferir, em linhas gerais, que o PET tem oportunizado um processo formativo que se qualifica por meio de ações coletivas que integram comunidade acadêmica e escolas principalmente, proporcionando aos seus integrantes pensar em seu futuro profissional, majoritariamente como docentes, além de vislumbrar possibilidades de continuidade da formação. A seguir, cada um desses temas gerais foi analisado mais detalhadamente.

\section{O trabalho coletivo: o grupo}

A análise mais atenta dos materiais escritos relevou que o trabalho coletivo propicia um meio em que as interações sociais são inevitáveis. Inevitável também são as tensões geradas por diversas razões e circunstâncias. Provavelmente em razão disso, a consciência de "grupo" emergiu nos resultados, revelando aprendizados sobre atitudes e valores.

[...] Venho também aprendendo com muitas outras situações, como lidar com as diferentes circunstâncias, saber ouvir todas as opiniões, como resolver problemas em grupo, discutir diferentes temas melhorando assim o meu senso crítico, a minha argumentação, a forma de se expressar e lidar com público [...]. Raquel (grifos dos autores). 
[...] Para trabalhar em grupo, tive que aprender como lidar com pessoas que são diferentes de mim, ouvir opiniões que são contrárias a minha. [...]. O PET Química permite o convívio com pessoas de diferentes idades, religiões, opiniões, cultura [...] (o integrante) que precisa tomar decisões. Rosa (grifos dos autores).

Outro aspecto importante é que ele não ajuda apenas na vida acadêmica [...] ajuda na vida pessoal, na relação com as outras pessoas, falar em público $e$ trabalhar em um grupo com várias diversidades de personalidade. Nora (grifos dos autores).

É importante ressaltar que o PET ajuda no desenvolvimento pessoal de cada um, pois a partir da convivência em grupo podemos desenvolver as nossas relações afetivas uns com os outros de alguma forma. Trabalhos em público, eventos que trazem pessoas de fora da universidade são experiência únicas que auxiliam diretamente na nossa forma de se relacionar e se comunicar com os outros. Estela (grifos dos autores).

As situações de tensionamento exigem também estratégias de enfrentamento, a partir das quais os estudantes precisam lidar e, sobretudo, aprender. Os relatos indicam que as estratégias de superação de tensões perpassam o desenvolvimento pessoal e aprendizagens de natureza interpessoal e inserção social, dentre elas "ouvir opiniões contrárias", respeitar diferenças, ser capaz de se expressar e melhorar a argumentação. Destaca-se ainda aspectos metacognitivos, em que reconhecem aquilo que precisa ser melhorado, tais como a capacidade de relacionamento interpessoal, de comunicação e argumentativa. Depreende-se, portanto, aprendizagens de natureza atitudinal, que influenciam o comportamento e o modo de analisar e se posicionar no grupo. O trabalho coletivo precípuo de um grupo (PET) exige avaliação de informações, contraste de posicionamentos, argumentação, conclusões e tomadas de decisões com base em critérios.

Assim, os processos vinculados à compreensão e elaboração dos conceitos associados ao valor, somados à reflexão e tomada de posição que comporta, envolvem um processo marcado pela necessidade de elaborações complexas de caráter pessoal. Ao mesmo tempo, a vinculação afetiva necessária para que o que se compreendeu seja interiorizado e apropriado implica a necessidade de estabelecer relações afetivas, que estão condicionadas pelas necessidades pessoais, o ambiente, o contexto e a ascendência das pessoas ou coletividades que promovem a reflexão ou a identificação com os valores que se promovem (ZABALA, p.47, 1998). 
Dois conhecimentos ficam evidentes, o respeito/capacidade de ouvir outras opiniões, e a comunicação (falar com o outro e em público). Em função das reuniões serem coletivas, fazer-se ouvir e ter seu ponto de vista considerado exige que os petianos comuniquem-se em grupo/em público. Em um segundo momento, emerge a capacidade de argumentação, uma vez que apenas ser capaz de se expressar é insuficiente para que uma decisão seja tomada. Os argumentos entram mais fortemente em vigor.

Ressalta-se que o caráter social e de coletividade é uma dimensão essencial no campo da formação docente. Ainda que essa vivência durante o curso de graduação não garanta a cooperação e solidariedade na atuação profissional, estas sem dúvida passam pela formação. A dimensão social do trabalho docente é própria da ação humana. As interações sociais no grupo são momentos importantes que propiciam trocas, compartilhamento e ajuda mútua, em que cada um participa com suas experiências, visões, saberes, anseios, necessidades, preocupações e limitações.

A disponibilidade para o diálogo e para a escuta são saberes fundamentais na prática do professor apontados por Paulo Freire (2009, p.136): “O sujeito que se abre ao mundo e aos outros inaugura com seu gesto a relação dialógica em que se confirma como inquietação e curiosidade, como inconclusão em permanente movimento na História". Trata-se da própria abertura à aprendizagem em que se funda a necessidade de contínua formação dos sujeitos.

Particularmente no campo da formação de professores de Química, Maldaner (2006) pontua que o grupo possibilita a produção de novos significados, capazes de mudar a prática da sala de aula, em que cada sujeito participa com suas crenças sobre questões ligadas à química, ao conhecimento, ao ensino, à aprendizagem e como isso ocorrem em sala de aula. Nessa perspectiva, a constituição do sujeito, suas características individuais, como personalidade, hábitos, modos de agir, capacidade mental etc., dependem de suas interações com o meio social em que vive (REGO, 2000).

As mudanças que ocorrem no professor, ao longo do seu desenvolvimento, estão associadas às interações estabelecidas com o meio e com os sujeitos que a ele pertencem e dele participam, com a cultura e as histórias de vida que ali se reconstroem. A tutoria funciona não pela imposição, mas pela colaboração e cooperação. É importante que a formação dos professores aconteça na relação com a coletividade, em espaços interativos de estudos e 
reflexão. Nesse aspecto, é possível reconhecer, a despeito das tensões, que o ambiente do PET é favorável a tais aprendizagens, auxiliando o desenvolvimento de atitudes, valores e procedimentos. A comunicação, materializada pelo binômio indicotomizável fala-escuta, fomenta esse desenvolvimento mútuo dos participantes, como coloca Freire (p.117):

De um lado, me proporciona que, ao escutar, como sujeito e não como objeto, a fala comunicante de alguém, procure entrar no movimento interno do seu pensamento, virando linguagem; de outro, torna possível a quem fala, realmente comprometido com comunicar e não com fazer puros comunicados, escutar a indagação, a dúvida, a criação de quem escutou.

Assim, pode-se entrever que o Programa de Educação Tutorial está ligado ao processo de formação social dos sujeitos participantes, com elementos fortemente ligados à vivência intensa de um processo afetivo-emocional e que reverberam positivamente para a atuação profissional docente. Igualmente importante é a noção do papel da comunidade, acadêmica ou não, neste processo.

\section{Interação com a(s) comunidade(s)}

Outras referências encontradas nos dados de pesquisa que impactam os petianos são relativas ao contato com comunidade, tanto a comunidade acadêmica (do curso específico e da universidade em geral) quanto a comunidade externa à universidade. Tal presença é explicada fundamentalmente em virtude da natureza das ações do PET, cujo público-alvo é majoritariamente este. Nesses termos, os petianos reconhecem algumas atividades de inserção fora da universidade como impactantes em seu processo formativo.

Lembrando que o PET é um programa que trabalha com o tripé da Universidade - ensino, pesquisa e extensão -, o grupo PET Química também possui seu grau de relevância na comunidade em que está inserido, como isso pode ser notado? É simples responder a essa pergunta quando se entende que o ensino e a pesquisa devem possuir como objetivo a extensão, assim, a comunidade é a beneficiada. No PET Química, podemos citar como exemplo as atividades realizadas para os alunos de escolas públicas da região mais próxima e também dos municípios mais próximos. Abigail (grifos dos autores). 
A divulgação científica como nos projetos de extensão que leva alunos de outras cidades a universidade, se faz muito importante na vida daqueles que participam, podendo fazer a diferença. Como também nas outras formas de divulgar a ciência. Fernandes (grifos dos autores).

Como citado anteriormente, a universidade e o PET estão pautados nas atividades de extensão, juntamente com a pesquisa e o ensino. O termo extensão, por exemplo, foi citado em 11 das 12 narrativas produzidas, aparecendo 19 vezes no total. Quando integrados, pesquisa e ensino culminam na extensão dos saberes produzidos à comunidade, visando o desenvolvimento mútuo mediante trocas destes saberes e, consequentemente, resultando na produção de outros conhecimentos em confronto com a realidade.

As atividades desenvolvidas com comunidades escolares ou do entorno da universidade fomentam capacidades procedimentais, que se relacionam aos quatro pilares básicos propostos por Zabala (1998): realização de ações, exercitação, reflexão sobre a própria atividade, aplicação em contextos diferenciados.

Na universidade é sua, ficamos em contato direto com o público, muitas vezes crianças que nem sabem o que é química e realizamos a atividade como divulgação científica tendo que adequar toda a linguagem científica que descrevemos os fenômenos a uma linguagem que o nosso público compreenda [...]. Fausto (grifos dos autores).

Uma boa graduação também vai além da sala de aula, assim o PET Química também contribui na graduação do petiano, proporcionando atividades que vão além da universidade ou que relacionam os conceitos vistos em sala de aula com a realidade da comunidade. Abigail (grifos dos autores).

[...] por meio da extensão a universidade se insere no meio externo a ela, pensando em métodos de levar a sociedade o que foi produzido, tendo em vista que a sociedade configura o ente financiador da universidade [pública]. Neide

Nos relatos destacados os integrantes citaram explicitamente o contato com um público não universitário como elemento desencadeador de aprendizagens. A necessidade de se pensar na linguagem a ser empegada objetivando uma melhora na comunicação com o público, bem como as relações estabelecidas com uma realidade mais concreta promovem um pensamento mais sistemático sobre o papel dos envolvidos e do próprio PET na integração com a comunidade. Maldaner (2006) aponta a necessidade de que a criação pedagógica na formação 
de professores de química se dê de forma coletiva, estando no bojo deste processo a compreensão da linguagem como constitutiva do pensamento e mediadora das ações. Tais capacidades são ainda atinentes aos aspectos procedimentais da profissão docente e se relacionam à exercitação no grupo para a subsequente problematização em outros contextos. 0 educar está concatenado à compreensão da sociedade e ao papel que as pessoas têm nela. Por conseguinte, a inserção do grupo em diferentes meios sociais é fundamental para a formação desses estudantes. Para Zabala (1998, p.28):

A capacidade de uma pessoa para se relacionar depende das experiências que vive, e as instituições educacionais são um dos lugares preferenciais, nesta época, para se estabelecer vínculos e relações que condicionam e definem as próprias concepções pessoais sobre si mesmo e sobre os demais.

A aprendizagem de conteúdos procedimentais é fruto da realização das ações que compõem o procedimento. O múltiplo exercício desta atividade e a reflexão sobre a própria atividade permitirá tomar consciência de sua atuação. Quando refletem conscientemente sobre a necessidade de adequação da linguagem e a importância de relacionarem o que abordam com a realidade objetiva, direcionam a aplicação do procedimento para estes contextos. Nessa questão, percebe-se que as atividades do PET permitem promover conteúdos para múltiplos exercícios, reflexões e aplicação dos procedimentos em diferentes contextos.

As atividades de extensão têm me possibilitado conhecer cada vez mais a sociedade a qual pretendo atuar de forma mais efetiva, principalmente as realidades das escolas públicas ao qual almejo exercer minha profissão docente, essa aproximação da realidade durante o processo de formação já me faz refletir sobre minhas futuras atitudes em busca de modificá-la. [...] o PET me proporcionou uma vivência fora da comunidade acadêmica que foi capaz de fomentar assim a minha construção como cidadã. Raquel (grifos dos autores).

A educação tutorial na formação universitária contribui para formar um aluno com autonomia no trato com o conhecimento, uma visão mais humanista nos processos de avanço científico, a conduta cidadã em relação as demandas da sociedade, desenvolvendo ainda a competência no aluno de identificar que há outros espaços de aprendizagem, e isso pode ser proporcionado pela extensão. Neide (grifos dos autores).

Novamente há referência a extensão e a interação na universidade e fora dela como 
desencadeadoras de aprendizagens, em especial a capacidade de pensar sobre a realidade em que atuam/atuarão. Para Freire (2009, p.41):

Uma das tarefas mais importantes da prática educativo-crítica é propiciar condições em que os educandos em suas relações uns com os outros e todos com o professor ou a professora ensaiam a experiência profunda de assumir. Assumir-se como ser social e histórico como ser pensante, comunicante, transformador, criador, realizador de sonhos, capaz de ter raiva porque capaz de amar.

Acrescenta-se, deste modo, que o compromisso com as atitudes e procedimentos vai além da obrigatoriedade da instituição ou do programa em interagir com a comunidade, passando a ser marcado por complexas elaborações individuais que integram o campo emocional. Zabala (1998, p.47) discute que "esta vinculação afetiva ainda é maior quando nos fixamos em atitudes, já que muitas delas são o resultado ou o reflexo das imagens, dos símbolos ou experiências promovidas a partir de modelos surgidos dos grupos ou das pessoas às quais nos sentimos vinculados". Ainda para este autor, aprende-se uma atividade quando o sujeito pensa, sente e atua de forma mais ou menos constante frente a um objeto concreto. Tais atitudes variam da intuição, do automatismo até uma consciência mais definida. Provavelmente, o protagonismo dos petianos e, ao mesmo tempo, o caráter colaborativo frente o objeto é que auxilia a definição da consciência do saber ser e saber fazer, ou nas palavras freirianas, do assumir-se, necessários às atividades arroladas. Assim, as aprendizagens desdobram-se para o âmbito do próprio curso.

o PET Química oferece certo suporte para o curso de Química, como exemplo, posso citar a realização de seminários e debates que possuem por público alvo alunos do curso da graduação, o apoio do grupo frente à organização de eventos do curso, como simpósios [...]. Desse modo, podemos compreender que a atuação do PET Química no curso de Química auxilia, principalmente, os estudantes do curso, considerando que as atividades do grupo também são voltadas para os alunos da graduação e o suporte que o grupo dá ao curso. Abigail (grifos dos autores).

[...] este programa envolve o ensino, pesquisa e a extensão, ou seja, as principais características da universidade. Além disso quem é contemplado por esse programa tem várias experiências positivas ao longo do curso que só a grade normal não ofertaria. [...]. Acredito que os alunos quando participem de algum 
modo [...] tenham um olhar diferenciado para possíveis situações no seu campo de trabalho e pessoal. Nora.

Esta vinculação do programa com o curso potencializa e oportuniza não somente aos petianos, mas a todos que participam de suas ações, um processo formativo complementar ao obrigatório. Caldas e Machado (2014) apresentam como resultados a importância da educação cooperativa no modelo tutorial como ponto de partida para a produção do conhecimento e a integração da universidade junto à sua comunidade de atuação. A integração com o curso é positiva e recomendada, pois se constitui como um dos objetivos do programa a preocupação com a graduação. Descolado de seu contexto, a potencialidade de aprendizagem proporcionada seria menor e menos significativa ao processo formativo de seus integrantes.

\section{Experiências individuais singulares}

O desenvolvimento pessoal mediante experiências individuais foi o tema geral de maior destaque dado pelos petianos, com maior diversidade de descritores e grupos de aprendizagem. Em maior ou menor grau, sete grupos principais de aprendizagens puderam ser depreendidos: respeito a individualidades; comunicação; organização/realização e responsabilidade por tarefas; aspectos ligados à docência (mediação pedagógica); interpretação textual; revisão de conceitos; análise do contexto/sociedade. Como descritores principais emergiram experiências (13 menções em 7 narrativas), exercer/prática docente/ensino (10 situações em 9 narrativas) e aprendizado. Algumas aprendizagens foram similares ou identificadas a partir de outros temas gerais, revelando que estão interconectas e não separadas. O diferencial nessa situação, todavia, é a referência ao "eu" como sujeito da ação.

Pois atuando em grupo tenho aprendido a lidar com as personalidades individuais de cada pessoa, reafirmando ainda mais dentro de mim a importância do respeito pelo próximo. Raquel (grifos dos autores).

O programa nos oportuniza diversas situações em que lidamos com estudantes, com professores, com palestrantes, fazendo com que nos tornemos ativos dentro e fora da sala de aula, pois antes de participar do programa não via a universidade fora da sala de aula, não me via realizando atividade que eu fosse o responsável. Caio (grifos dos autores). 
[...] todas as atividades, que foram citadas ou não, o próprio grupo, contribuiu de uma forma inigualável na minha formação, aprendi a tomar a frente das coisas, tomar a responsabilidade para mim. Hoje posso dizer que tenho mais desenvoltura para falar em público, consigo ser mais desinibida em relação a isso, e sei que isso me ajudará muito no meu futuro. Rosa (grifos dos autores).

Zabala (1998) aponta que promover atividades autônomas e mentalmente autoestruturantes favorecem os sujeitos compreenderem o que fazem e como fazem. Por conseguinte, ao terem que "lidar com personalidades individuais", "tomar frente das coisas" ou conviver com pessoas diferentes, os petianos experimentam um processo que exige atitudes e procedimentos específicos. Ao narrarem estas experiências, põe em evidência aquilo que deixou marcas. Relatam ainda aspectos que os auxiliam no curso e na prática profissional futura.

As atividades realizadas podem caracterizar o grupo PET Química como um espaço para debates e aprimoramento de conceitos químicos, o que consequentemente aprimora a formação do petiano. Atividades como 'A universidade é sua' e 'ArtPET com Ciência', demandam tempo de organização, de discussão de conceitos químicos e de mediação, assim como um feedback após a realização que permite a discussão de erros e melhoras. [...] Também não posso deixar de fora as leituras realizadas em grupo de livros científicos $e$ de outros gêneros textuais que permitem ao petiano uma maior capacidade de argumentação e interpretação, ambas as coisas necessárias na atuação profissional de um professor. Abigail (grifos dos autores).

O integrante tem a oportunidade de preparar-se melhor para o exercício da docência, o que implica o incessante estudo das teorias e conceitos científicos, a pesquisa em educação química a fim de diagnosticar e solucionar problemas neste âmbito, e a extensão, com a finalidade de aplicar os conhecimentos em função da contribuição da formação do cidadão. Ester (grifos dos autores).

Tais excertos demonstram que a educação tutorial proporciona meios não somente para o fazer, como, principalmente, o pensar sobre o fazer. De tal forma, a tutoria torna-se uma prática (auto)regulada que estimula o trabalho planejado (FRISON, 2013). Vale destacar que o processo formativo universitário, em seu maior tempo, é moldado por uma concepção transmissiva de ensino. Daí o destaque para as experiências formativas do PET, pois estas procuram romper com esse viés. Os participantes do programa experimentam ações (auto)dirigidas autonomamente. Há uma relação direta com a necessidade de os estudantes assumirem, desde o processo de formação inicial, a condição de sujeitos e não objetos da aprendizagem. 
Se, na experiência de minha formação, que deve ser permanente, começo por aceitar que o formador é o sujeito em relação a quem me considero objeto (...) me considero um paciente que recebe os conhecimentos-conteúdosacumulados (....). Nesta forma de compreender e de viver o processo formador, eu, objeto agora, terei a possibilidade, amanhã, de me tornar falso sujeito da "formação" do futuro objeto de meu ato formador. É preciso que, pelo contrário, desde os começos do processo, vá ficando cada vez mais claro que, embora diferentes entre si, quem forma se forma e re-forma ao formar e quem é formado forma-se e forma ao ser formado (FREIRE, 2009, p.22-23).

Esta passagem, de algo externo e interpessoal, para a dimensão interna e intrapsíquica não é feita por imposição exterior, mas pelo envolvimento e transformação do próprio indivíduo. A tutoria não é uma metodologia para incentivar ou facilitar o êxito, mas um processo que permite criar caminhos e um ambiente pró-ativo em que todos aprendam. As características diferenciadas deste processo estão intricadas a outros componentes da formação docente e suas especificidades.

Levando em consideração que faço parte de um curso de licenciatura em química as atividades de ensino são fundamentais, pois oportunizam experiências pedagógicas que apenas o curso regular não me proporciona. As atividades de ensino me fazem exercitar minhas práticas pedagógicas, também faz com que eu tenha por obrigação que revisar e aprofundar os meus conhecimentos já obtidos para que assim possa ensiná-los. Raquel (grifos dos autores).

Como o PET é composto por integrantes que cursam licenciatura em química nós buscamos em nossas atividades desmistificar alguns estereótipos, e ao passo que fazemos isso contribuímos para a nossa evolução acadêmica, por isso, há uma preocupação de como passar as informações em nossas atividades e projetos de extensão. Esse é um fator fundamental que faz, com toda certeza, que um professor que passou pelo o programa de educação tutorial seja diferenciado. [...] os alunos que fazem de algum modo parte de programas que desenvolva projetos voltados para a sociedade tenham um olhar diferenciado para possiveis situações no seu campo de trabalho e pessoal. Nora (grifos dos autores).

É marcante a identidade de um curso de licenciatura no programa. Um dos objetivos do PET é contribuir com a qualidade do ensino superior. Tendo em vista o fato de o grupo estar vinculado a um curso de formação de professores, suas ações implicam no pensamento da atividade docente, seja nos projetos de divulgação científica ou de formação interna (leituras, planejamento, avaliação). Por isso menções à docência e ao ensino estiveram presentes em 8 das 12 narrativas, revelando que a participação no programa está integrada ao curso, que por 
sua vez torna-se referência para a atuação do grupo.

Maldaner (2006) destaca a necessidade de os cursos de licenciatura proverem uma formação específica que permita o desenvolvimento de um profissional para além da reprodução de práticas. Conquanto seja esta responsabilidade do curso, grupos PET ligados especificamente às licenciaturas podem e precisam estar alinhados a este propósito uma vez que não existem senão dentro dos cursos. A isso se soma o envolvimento dos estudantes em práticas que se conectem à Educação Básica. Nesse sentido, as atividades de divulgação da ciência, que são centrais no planejamento do grupo, vêm cumprindo esse papel, não obstante também se deva reconhecer suas particularidades para a formação docente. Ao mesmo tempo em que são uma possibilidade de atuação e desenvolvimento de práticas educativas, a sala de aula abarca outras especificidades.

Em um contexto diferenciado da formação docente, Silva, Cruz e Camargo (2008/2009) investigaram as contribuições do PET para a formação em Enfermagem. Este estudo também revelou que a metodologia de trabalho favorece o amadurecimento profissional e pessoal, levando ao cumprimento de seu papel no que diz respeito à formação ampla, ao preparo de profissionais mais comprometidos com a realidade, e com o aprimoramento dos conhecimentos técnico-científicos.

Embora tenha havido menções a aprendizagens conceituais neste item ("revisar e aprofundar conhecimentos", "estudo de teorias e conceitos científicos"), silenciamentos ocorreram no detalhamento de quais são as aprendizagens técnico-conceituais. Conteúdos de natureza conceitual foram provavelmente desenvolvidos e podem não se fazer explícitos por outras razões. Infere-se que uma delas pode estar relacionada ao próprio instrumento de análise que não favoreceu a emersão destes aspectos. O fato de tais saberes constituírem-se em produtos da ciência, tais como modelos, teorias, princípios e, por outro lado, a narrativa ser experiencial, portanto, relacionada a fatos, podem ter contribuído para que este tenha sido do foco.

\section{Perspectivas de futuro}

Uma última dimensão depreendida se relaciona às perspectivas futuras. A palavra "futuro" foi o principal descritor, sendo empregada em sete ocasiões e em cinco cartas diferentes. A participação no programa proporciona o contato entre estudantes de diferentes 
estágios e percursos formativos, fazendo que possam acompanhar ou se espelhar nos colegas e pensar além da graduação.

Posso dizer que o grupo consegue, na maioria das vezes, fazer o com o que o discente tenha destaque [...]. Falo isso porque temos como exemplo, alguns petianos egressos que só cresceram depois da graduação. Rosa (grifos dos autores).

Para mais além, espero que todas essas contribuições que já se faz presente, se multiplicarem, de forma a conseguir me superar cada dia mais, concluir a graduação e conseguir mestrado, quem sabe um doutorado, sempre se fará presente os ensinamentos que o PET ainda vai deixar em minha vida. Fernandes (grifos dos autores).

As experiências proporcionadas contribuem tanto para minha formação acadêmica quanto minha formação humana. Além das contribuições que posso evidenciar em meu presente, acredito que no meu futuro profissional muitas delas serão elementares. Raquel (grifos dos autores).

Dessa forma, este contato molda atitudes dos petianos no que se refere ao planejamento pessoal, ao compromisso com o curso e a opção pela profissão.

Ainda olhando para a graduação do petiano, a não reprovação em disciplinas [...] oferece uma grande contribuição, considerando que desse modo o petiano se formará no calendário previsto e subtende que a graduação será melhor aproveitada. Sinceramente, e este é um relato pessoal, a não permissão de reprovação no programa ajuda a manter o foco e a não desistir, não fosse o PET, eu teria desistido de pelo menos 3 disciplinas, isso teria trazido prejuízos gigantescos para a minha graduação, mas eu optei por persistir (por causa do compromisso com o PET Química) Abigail (grifos dos autores).

Além dessas experiências proporcionadas, o PET me auxilia a buscar sempre o êxito em tudo que faço, como também a aprimorar e melhorar todas as minhas incapacidades. [...] atuando em grupo e a cada dia me redescobrindo. E que com o passar do tempo, toda a bagagem que estou adquirindo venha a dar frutos. Cleide_(grifos dos autores).

Ele (programa) me ajuda não só nas aulas, mas na vida [...], agora eu consigo me ver no futuro como professor, pois antes tinha receio da docência, mas o PET Química me fez a docência com outros olhos, como aliada, fico muito feliz por isso. Danilo (grifos dos autores).

Além de modificar o pensamento de alguns acerca daquilo que desejam realizar 
futuramente, fazendo emergir uma predisposição pela atividade docente, os petianos demonstram confiança na qualidade de suas formações crendo que, de algum modo, isso lhes resultará benefícios pessoais. Souza e Gomes Júnior (2015) corroboram tais perspectivas em um estudo sobre o tempo de graduação, evasão e inserção profissional de ex-petianos. Os autores investigaram um grupo PET em um curso de Física também do Nordeste brasileiro. Seus resultados apontam que os bolsistas, em média, concluem o curso de graduação mais rapidamente que os demais, além de exibirem menor índice de evasão. Também reportam a inserção de cerca de 95\% dos ex-integrantes como profissionais, especialmente em universidades.

Pensar a atividade profissional ou os percursos futuros carrega um componente afetivo. Os aspectos atitudinais são fortemente influenciados tanto pela dimensão cognitiva quanto afetiva. Segundo Zabala (1998, p.83), "os pensamentos, os sentimentos, e comportamento de uma pessoa não dependem só do socialmente estabelecido, como, sobretudo, das relações pessoais que cada um estabelece com o objeto da atitude ou valor". Como já discutido em outro momento, a natureza e a filosofia de ação do grupo estão densamente ancoradas no curso, que é de formação de professores, o que parece provocar e sensibilizar os petianos a estabelecer uma atitude diferenciada sobre essa atuação e compromisso. Freire $(2009$, p.107) acena que:

\footnotetext{
Ninguém é sujeito da autonomia de ninguém. Por outro lado, ninguém amadurece de repente aos 25 anos. [...] A autonomia, enquanto amadurecimento do ser para si, é processo, é vir a ser. Não ocorre em data marcada. É nesse sentido que uma pedagogia da autonomia tem de estar centrada em experiências estimuladoras da decisão e da responsabilidade, vale dizer, em experiências respeitosas da liberdade.
}

Pode-se inferir, portanto, que independente dessa atuação docente concretizar-se futuramente, o PET vem contribuindo com a formação acadêmica de graduação de modo a refletirem sobre o campo profissional, criando experiências para esta tomada de decisão e responsabilidade.

\section{Considerações Finais}

As cartas narrativas demonstraram-se um instrumento útil para a (auto)análise dos 
estudantes sobre contribuições formativas e aprendizagens fomentadas pelo PET. Por meio da produção textual puderam rememorar dificuldades, (re)pensar estratégias, descrever aprendizagens e ponderar sobre a atuação do programa, fatores que contribuem em sua (auto)regulação.

Nesse sentido, a pesquisa revelou aspectos considerados pertinentes no que concerne às aprendizagens proporcionadas pela educação tutorial e à própria constituição identitária do grupo PET Química. Destacaram-se 4 grandes temas que impactam a formação: o grupo, interação com comunidade(s), experiências individuais, perspectivas futuras. Cada um destes temas compõe o processo formativo e as preocupações dos petianos ao longo do percurso. Em linhas gerais, o PET tem oportunizado um processo formativo configurado por ações coletivas que integram comunidade acadêmica e escolas principalmente, proporcionando aos seus integrantes pensar em seu futuro profissional, majoritariamente como docentes, além de vislumbrar possibilidades de continuidade da formação. Depreendeu-se a importância dos enfrentamentos, do diálogo, da autonomia na gestão de ações, os quais indiciam o cumprimento dos objetivos estabelecidos para o Programa de Educação Tutorial, especialmente quanto ao estímulo à formação de qualidade, crítica e comprometida socialmente. Os dados revelaram ainda uma identidade marcante do grupo no tange às atividades de ensino/divulgação e à formação docente futura.

O instrumento de análise também permitiu averiguar silenciamentos. Não foram explicitadas, por exemplo, aprendizagens de natureza conceitual atinentes à química e ao que é ensinar (química). Assim, maior atenção pode ser dada a tais tipos de conhecimentos durante o planejamento anual das atividades, nas etapas preparatórias da implementação das ações, bem como na (auto)avaliação. Esta é uma contribuição importante que as narrativas como instrumento de análise educacional podem proporcionar para os próximos planejamentos anuais. Nessa direção, narrativas podem se configurar em uma atividade reflexiva que proporciona a retroalimentação e a gestão de programas educacionais com características similares. Um dos aspectos a ser destacado é o compromisso com a melhoria do processo educativo e das ações que são (re)programadas. Um ponto negativo deste instrumento analítico educacional é o tempo demandado para análise dos dados, pois é exigido uma imersão profunda nas informações, fato que desaconselharia seu emprego na avaliação de grandes grupos em um curto espaço de tempo. 


\section{Referências}

BARDIN, L. Análise de conteúdo. Lisboa: Edições 70, 2011.

BRASIL. Lei $n^{\circ} 9394$ de 20 de dezembro de 1996. Lei das Diretrizes e Bases da Educação Nacional (LDB). Diário Oficial da União, seção 1, 1996.

BRASIL. Portaria n 343 de 24 de abril de 2013. Diário Oficial da União, seção 1, 24-25, 2013.

BRASIL. Lei no 13.005, de 25 de junho de 2014. Plano Nacional de Educação 2014-2024. Diário Oficial da União, edição extra de 26 jun. 2014, p. 1-8, 2014

BRUTTEN, E. A tutoria na educação: suas origens e concepções. In: Colóquio da Associação de Estudos e Investigação em Educação de Portugal (AFIRSE/AIPELF), 16., 2008, Lisboa: Universidade de Lisboa. Atas [...], 2008. p. 1-10.

CALDAS, R. F.; MACHADO, L. S. Integração comunitária através da educação cooperativa: os programas de ensino e pesquisa da UNESP/FFC. Revista Brasileira de Educação em Ciência da Informação, v.1, n.1, p.19-34, 2014.

CARABALLO, A. M. F. La tutoría académica en la enseñanza universitária: el caso de la UDELAR. ETD: Educação Temática Digital, v.14, n.2, p.38-60, 2012.

CUNHA, M. I. Conta-me agora! as narrativas como alternativas pedagógicas na pesquisa e no ensino. Revista da Faculdade de Educação, v.23, n.1/2, p.185-195, 1997.

FREIRE, P. Pedagogia do oprimido. 43.ed. Rio de Janeiro: Paz e Terra, 2005.

FREIRE, P. Pedagogia da autonomia: saberes necessários à prática educativa. 40.reimp. Rio de Janeiro: Paz e Terra, 2009.

FRISON, L. M. B. Tutoria: uma prática de ensino autorregulada utilizada no ensino superior. Reflexão \& Ação, v.21, n.2, p.66-81, 2013.

LAZARO MARTINEZ, A. La acción tutorial de la función docente universitaria. Revista Complutense de Educación, v.8, n.1, p.234-252, 1997.

MALDANER, O. A. A formação inicial e continuada de professores de química: professores/pesquisadores. 3.ed. Ijuí: Unijuí, 2006.

REGO, T. C. A origem da singularidade humana na visão dos educadores. Cadernos Cedes, v.35, p.96-113, 2000.

RIBEIRO, C. Metacognição: um apoio ao processo de aprendizagem. Psicologia: Reflexão e 
Crítica, v.16, n.1, 109-116, 2003.

SILVA, V. A., CRUZ, J. B. R. L.; CAMARGO, C. L. O programa de educação tutorial (PET) como instrumento pedagógico para os alunos de enfermagem. Revista Baiana de Enfermagem, v.22/23, n.1, 2, 3, p.57-66, 2008/2009.

SOUZA, R. M.; GOMES JÚNIOR, S. R. Programa de educação tutorial: avanços na formação em física no Rio Grande do Norte. Revista Brasileira de Ensino de Física, v.37, n.1, p.1501-1501-5, 2015.

ZABALA, A. A prática educativa: como ensinar. Porto Alegre: Artmed, 1998.

\section{AGRADECIMENTOS}

Os autores agradecem aos participantes da pesquisa que cederam gentilmente seu tempo e ao Fundo Nacional de Desenvolvimento da Educação (FNDE) pelas bolsas e financiamento do Programa de Educação Tutorial.

Recebido em julho 2019.

Aprovado em maio 2020. 